\title{
Rough Sets and DEA - a hybrid model for technology assessment
}

\author{
Ewa Chodakowska ${ }^{1 *}$, and Joanicjusz Nazarko ${ }^{1}$ \\ ${ }^{1}$ Bialystok U niversity of Technology, F aculty of Engineering M anagement, Wiejska 45A, \\ 15-351 Bialystok, Poland
}

\begin{abstract}
Technology management in complex ecosystems requires advanced technology assessment tools. Data Envelopment A nalysis (DEA) is a powerful tool for a multi-criteria comparative performance assessment of different objects (Decision Making Unit - DMU) in the same class. However, the DEA method is capable of adequately differentiating DMUs only when the number of analysed criteria is a few times less than the number of DMUs. A pplication of DEA in technology assessment requires prior data redundancy reduction due to the multiplicity of technology assessment criteria. The literature suggests various approaches to limiting the cardinality of the criteria sets for the performance analysis using the DEA method. One of the popular approaches is to create synthetic criteria by means of the Principle Component A nalysis (PCA ). This paper, in turn, proposes a sophisticated rough sets concept. Due to the nature of technology analysis, namely, a small number of objects and many criteria with linguistic values, the proposed approach based on the concept of rough sets seems to be appropriate.
\end{abstract}

\section{Introduction}

The primary goal of technology assessment is to identify technologies that can generate the highest economic and/or social benefits to prioritise future investments. Technology assessment is a prospective activity that allows selecting the research and innovation projects which may translate into faster development of regions. At the enterprise level, proper management of technologies is the basis for building a long-term competitive advantage, determining the ability to sustain development. The importance of the problem of proper prioritization of technology means that different approaches, methods and tools are being developed in the area of technology assessment [1-3].

The discussion on the portfolio of methods with the potential to be used in technology assessment is the subject of many publications: [4-7]. One of the most popular typologies presented Popper (2008) [8] who proposed a typology of 33 foresight methods: quantitative, qualitative, mixed, and exploratory or normative. Cagnin et al. (2013) [9] suggest combining methods traditionally classified as quantitative with qualitative due to the fact that qualitative may ensure greater involvement of potential stakeholders, while the quantitative higher objectivity of the assessment. Triangulation understood as the integration of various types

* Corresponding author: e.chodakowska@pb.edu.pl 
of information and techniques is indicated as an approach with higher value in use for decision-makers. However, the review of foresight projects shows the domination of quality methods (see: [10, 8, 10-11]). In the implemented foresight projects, one of the most frequently used methods was the Delphi method [12-14].

Data Envelopment Analysis (DEA) is a powerful tool for a multi-criteria comparative performance assessment of different objects (Decision Making Unit — DMU), and it is widely used for enterprises, non-profit organisations and systems' evaluation. A few published applications also indicate its legitimacy and suitability for technology assessment. However, DEA is still underused for technology management. Among the published works, significant numbers concern the assessment of technology considering the need for sustainable development, utilising the advantage of DEA to include information on undesirable effects of technology development. For example, Kwon et al. (2017) [15] assessed European countries regarding green-energy technology using a two-stage DEA evaluating energy generation with regards to C02. Environmental performance of European countries was also of the object interest in Chodakowska and Nazarko (2017) work [16].

Sueyoshi and Goto (2014) [17] examined the corporate sustainability of the Japanese industrial sector. Fan et al. (2015) [18] assessed the potential efficiency of twenty CO2 utilisation technologies in China. Shabani and Saen (2014) [19] analysed eco-efficient technologies of cooling towers in a power plant. Liu et al. (2013) [20] considered ecoefficiency of water systems in 31 provinces, regions, and municipalities in China.

There are also works on technology analysis by DEA, which consider non-ecological criteria. Lee et al. (2013) [21] used fuzzy AHP and DEA to prioritise R\&D resources in energy technologies to establish the strategy against high oil prices. Lee et al. (2008) [22] set R\&D priorities in technology foresight context. Yu and Lee (2013) [23] presented combining scores calculation using DEA and AHP for clustering similar technologies established based on required input resources to select promising emerging nanotechnology.

Numerous works are available demonstrating new approaches or models of DEA in the context of technology analysis. Amin and Emrouznejad (2013) [24] proposed a new noniterative DEA on the dataset of robot selection from [25]. Earlier, using the same data set, Alinezhad et al. (2011) [26] proposed input-oriented DEA CCR multiple-criteria decisionmaking (MCDM) model. The dataset from [27] used Saen (2009) [28] to demonstrate an assurance region-nondiscretionary factor-imprecise DEA (AR-NF-IDEA) models for technology analysis.

In the technology analysis, it is necessary to consider many stakeholders and many aspects of the assessment. The criteria taken into account in the analysis of technologies always result from the context of the assessment and are implied by the subject and field of analysis. The challenge of the data aggregation stage is to reach a consensus on the weights of individual criteria or areas that will balance different opinions, values, needs. Klincewicz and Manikowski (2013) [29] developed a set of 184 detailed evaluation criteria, divided into 12 thematic groups: innovation, competitiveness, strategy, organisation-supplier experience, the importance of technology for the organisation-supplier, marketing, technology applications, technical aspects, production technologies, patent protection, social and ethical aspects, and ecology. In the situation of a specific assessment, considering the purpose of the research task, the characteristic of criteria appropriate to the analysed technologies can be selected from the set, e.g. only economic, technological, ecological and social. Nevertheless, the set of criteria is usually quite large (for example, Technology Foresight in the Czech Republic: 35 criteria in 6 fields [30], NT FOR Podlaskie 2020: 21 criteria [31]).

The DEA method is capable of adequately differentiating DMUs only when the number of analysed criteria is a few times less than the number of DMUs. Application of DEA in technology assessment requires a prior data redundancy reduction due to the multiplicity of technology assessment criteria and, sometimes, subtle differences between them. Many 
approaches have been developed to reduce the number of evaluation criteria in the DEA framework. A popular choice is to create synthetic criteria using the Principle Component Analysis (PCA) [32-33]. Rough sets are primarily used for the induction of decision rules. Revett (2008) [34] discovered decision rules that predict the features influencing the outcomes measured clinically in a patient dataset. Yang and $\mathrm{Wu}$ (2009) [35] used the rough sets theory to induce decision rules to set significant symptoms of diseases on the basis of data from a Taiwanese otolaryngology clinic. The analysis of data and setting rules is often preceded by a cardinal reduction of attributes. Dimitras et al. (1999) [36] used a rough set to reduce and discriminate between enterprises to predict business failure. Both methods, i.e. PCA and rough sets, can be combined for the simplification of systems by the elimination of attributes whose values have no influence on decisions or do not distinguish objects. An algorithm for feature selection using PCA and rough sets in facial pattern recognition and mammogram experiments was proposed by Swiniarski and Skowron (2003) [37].

The contribution of this article is a proposition of a concept of rough sets to reduce the number of criteria in the context of technology analysis by DEA [38].

\section{Methods}

The rough set theory introduced by Pawlak (1982) [39] is founded on the assumption that each object is associated with some information, i.e. attributes. An object characterised by the same values of attributes is indiscernible (similar) given the available information [40].

Let $I S=\{U, A\}$ be an information system, where $U$ is non-empty, finite set of objects called the universe, and $A-$ a non-empty finite set of attributes. With every subset of attributes $B \subseteq A$, the indiscernibility relations are defined as:

$\operatorname{IND}(B)=\left\{\left(x, x^{\prime}\right) \epsilon U^{2}: \bigwedge_{a \in B} a(x)=a\left(x^{\prime}\right)\right\}$

Objects $X, x^{\prime}$ satisfying relations $\operatorname{IND}(B)$ are indiscernible by attributes from $B$. The partition of $U$ generated by $\operatorname{IND}(B)$ is denoted as $U / I N D(B)$.

An attribute $a \in B \subseteq A$ is dispensable in $B$ if $\operatorname{IND}(B)=\operatorname{IND}(B-\{a\})$, otherwise, $a$ is indispensable in $B$. The minimal subset $B \subseteq A$, such that $\operatorname{IND}(B)=\operatorname{IND}(A)$, is called a reduct of $A$. The set of all reducts of $A$ is denoted as $R E D(A)$. The intersection of reducts of $A$ is referred to as a core of $B \subseteq A$ : $\operatorname{CORE}(B)=\cap \operatorname{RED}(A)$. In other words, the reduct must be an independent set of attributes and must be able to distinguish between objects.

The idea of core and reducts illustrates the definition-based algorithm of discovery in Fig 1.

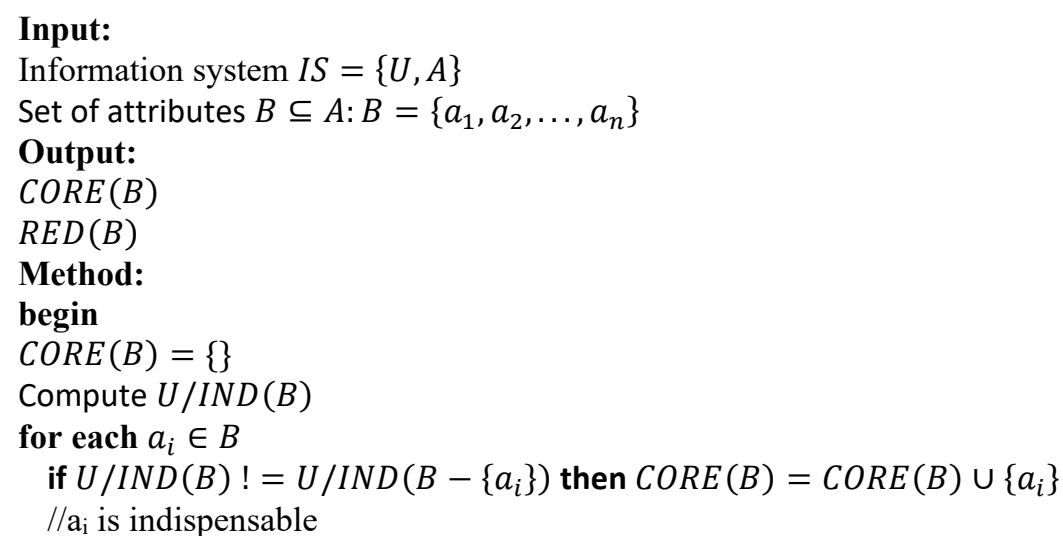




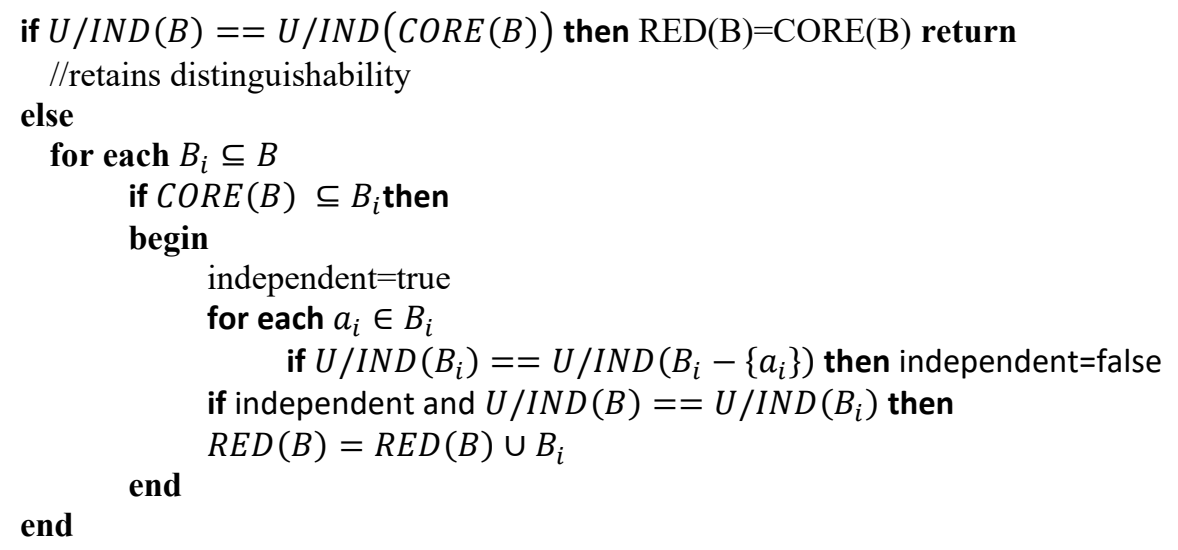

Fig. 1. Definition-based algorithm for the core and reducts

Due to the computational complexity of the definition-based algorithm given above, it is suggested to use the indiscernibility matrix $M(I S)$ of the information system: $M(I S)=$ $\left[c_{i j}\right]_{n x n}, \quad$ where $\quad c_{i j}=\left\{a \in A: a\left(x_{i}\right) \neq a\left(x_{j}\right)\right.$, for $\left.i, j=1,2, \ldots, n\right\} . \quad \operatorname{CORE}(B)=\{a \in$ $A: c_{i j}=\{a\}$ for $\left.1 \leq i, j \leq n\right\}$, consist of the attributes that are single in the matrix. $R E D(B)$ is the minimum subset of attributes and has a non-empty intersection with each non-empty element of the matrix $M(I S)$. The problem of finding a minimum or nearly minimum reducts is one of the main problems of the rough set theory. There are many propositions of reduct generations algorithms, both exact and approximate.

The selection of a satisfactory set of attributes from the obtained $R E D(B)$ should consider two criteria [36]: the reduct should contain as few attributes as possible, and the reduct should not miss the attributes judged by the decision-makers as the most significant.

The idea of attribute reduction using indiscernibility relations is an interesting proposition of preparing data for prioritising technology. Firstly, a typical task of technology assessment is a selection from a few technologies characterised by a dozen criteria. Attribute reduction methods based on a correlation matrix/covariance (like PCA) is not statistically valid. Secondly, technology assessment is usually done by linguistic descriptions on the scale. The answers are encoded, however, performing arithmetic operations on encoded values is associated with the appearance of the problem of an unintentional change in the relationship between answers.

DEA, originally proposed by Charnes et al. (1978) [41], evaluates technologies regarding potential effects/benefits (referred to as outputs in the DEA nomenclature) in relation to expenditure of implementation/development costs (inputs) based on a weighted sum of outputs to inputs. The weights are optimally selected for each unit being assessed to maximise its score using linear programming algorithms. The final score ranges from 0 to $100 \%$.

Considering the most appropriate DEA model among many possibilities and extensions, authors believe that the fuzzy DEA model is worth noting due to the aforementioned need to code linguistic responses. In addition, despite the limitation of the number of criteria using the rough set theory, the number of analysis objects in the technology assessment task will often not be significantly larger than the number of criteria. The result will be in a large subset of effective objects. Therefore, it will be reasonable to use a super-efficiency (SE) model proposed by Andersen and Petersen (1993) [42] to differentiate efficiency units (final efficiency score can exceed 100\%).

In summary, to evaluate the technology based on the proposed rough sets concept SE fuzzy DEA model is proposed: 
$\min \theta_{j_{o}}$

$\sum_{j=1, j \neq j_{O}}^{n} \lambda_{j} \tilde{x}_{i j} \leq \theta_{j_{o}} \tilde{x}_{i j_{O}}, \forall_{i}$

$\sum_{j=1, j \neq j_{o}}^{n} \lambda_{j} \tilde{y}_{r j} \geq \tilde{y}_{r j_{0}}, \forall_{r}$

$\lambda_{j} \geq 0, j=1, \ldots, n$

where:

$\theta_{j_{o}}$ - efficiency score of unit $j_{o}$,

$\lambda_{j}-$ the vector of weighs,

$\tilde{x}_{i j}=\left(x_{i j}^{l}, x_{i j}^{m}, x_{i j}^{u}\right)$ - triangular fuzzy input,

$\tilde{y}_{r j}=\left(y_{r j}^{l}, y_{r j}^{m}, y_{r j}^{u}\right)-$ triangular fuzzy output,

$m$ - the number of fuzzy inputs,

$s$ - the number of fuzzy outputs,

$n$ - the number of DMUs.

And the concept of the $\alpha$-cut was applied and two models which give upper and lower bounds and triangular fuzzy numbers as proposed by Azadeh and Alem (2010) [43]:

$$
\begin{aligned}
& \min \left(\theta_{j_{o}}\right)_{\alpha}^{U} \\
& \sum_{j=1, j \neq j_{o}}^{n} \lambda_{j}\left(\alpha x_{i j}^{m}+(1-\alpha) x_{i j}^{u}\right) \leq \theta_{j_{o}}\left(\alpha x_{i j_{O}}^{m}+(1-\alpha) x_{i j_{o}}^{l}\right) \\
& \sum_{j=1, j \neq j_{o}}^{n} \lambda_{j}\left(\alpha y_{r j}^{m}+(1-\alpha) y_{r j}^{l}\right) \geq\left(\alpha y_{r j_{O}}^{m}+(1-\alpha) y_{r j_{o}}^{l}\right) \\
& \forall r, i, \lambda_{j} \geq 0, j=1, \ldots, n \\
& \min \left(\theta_{j_{o}}\right)_{\alpha}^{L} \\
& \sum_{j=1, j \neq j_{o}}^{n} \lambda_{j}\left(\alpha x_{i j}^{m}+(1-\alpha) x_{i j}^{l}\right) \leq \theta_{j o}\left(\alpha x_{i j_{O}}^{m}+(1-\alpha) x_{i j_{o}}^{u}\right) \\
& \sum_{j=1, j \neq j_{o}}^{n} \lambda_{j}\left(\alpha y_{r j}^{m}+(1-\alpha) y_{r j}^{u}\right) \geq\left(\alpha y_{r j_{o}}^{m}+(1-\alpha) y_{r j_{o}}^{u}\right) \\
& \forall r, i, \lambda_{j} \geq 0, j=1, \ldots, n
\end{aligned}
$$

Both the DEA model and the fuzzy membership function have been chosen arbitrarily among many possibilities based on a subjective assessment of the simplicity of the solution.

The used hybrid rough sets, i.e. the fuzzy SE DEA model, for technology assessment scheme consist of a few stages as illustrated in Fig. 2

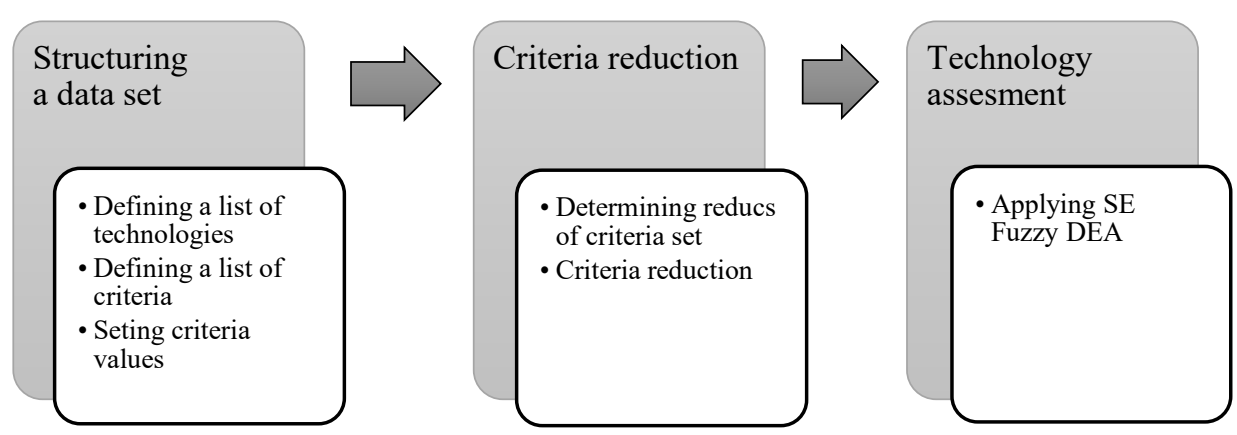

Fig. 2. Scheme of the hybrid rough SE fuzzy DEA model for the technology analysis

The first stage for the structuring of a dataset consists of the identification of available alternative technologies, defining criteria and setting criteria values. The data are collected through interviews with experts. Then obtained dataset is treated as IS and the number of criteria is limited to the use of the rough set rules. The DEA on reduced data allows prioritising technologies. 


\section{Results and discussions}

To illustrate the concept of the rough and fuzzy DEA method, the assumptions for four hypothetical technologies were made. Twelve variables were adopted: six input (resource) and six output (benefits) criteria with a range of values from a set of linguistic terms, respectively: three variants for inputs and two for outputs transcoded into fuzzy numbers. Tables 1 and 2 respectively present that linguistic terms code and random values. Linguistic values represent the answer from the questionnaire determining the cost/resource needed (weak, moderate, strong) and the importance/future positive effect (yes/no).

Table 1. Linguistic terms and appropriated fuzzy numbers

\begin{tabular}{|c|c|c|c|c|}
\hline \multirow{3}{*}{ Input } & Linguistic value & \multicolumn{2}{|c|}{ Fuzzy numbers } & Code \\
\cline { 2 - 5 } & Weakly & $(0,2,4)$ & $(0,0.2,0.4)$ & 0 \\
\cline { 2 - 5 } & Moderately & $(3,5,7)$ & $(0.3,0.5,0.7)$ & 1 \\
\cline { 2 - 5 } & Strongly & $(6,8,1)$ & $(0.6,0.8,1)$ & 2 \\
\hline \multirow{2}{*}{ Output } & Yes & $(0,3,6)$ & $(0,0.3,0.6)$ & 0 \\
\cline { 2 - 5 } & No & $(4,7,10)$ & $(0.4,0.7,1)$ & 1 \\
\hline
\end{tabular}

Table 2. Technology criteria values

\begin{tabular}{|c|c|c|c|c|c|c|c|c|c|c|c|c|}
\hline & \multicolumn{6}{|c|}{ Input } & \multicolumn{6}{|c|}{ Output } \\
\hline & $i_{1}$ & $i_{2}$ & $i_{3}$ & $i_{4}$ & $i_{5}$ & $i_{6}$ & $o_{1}$ & $O_{2}$ & $O_{3}$ & $O_{4}$ & $O_{5}$ & $o_{6}$ \\
\hline T1 & 1 & 0 & 0 & 1 & 2 & 0 & 0 & 0 & 0 & 0 & 1 & 1 \\
\hline $\mathrm{T} 2$ & 1 & 0 & 0 & 1 & 0 & 0 & 1 & 0 & 1 & 0 & 1 & 1 \\
\hline T3 & 2 & 1 & 2 & 2 & 0 & 0 & 1 & 1 & 1 & 0 & 1 & 1 \\
\hline T4 & 0 & 0 & 0 & 0 & 1 & 0 & 0 & 0 & 1 & 0 & 1 & 1 \\
\hline
\end{tabular}

Considering the input $I S$, the set of attributes $B=\left\{i_{1}, i_{2}, \ldots, i_{6}\right\}$ and the set of technologies $U / I N D(B)=\{T 1, T 2, T 3, T 4\}$, using the algorithm from Fig. 1: $\operatorname{CORE}(B)=\left\{i_{5}\right\}$ and $\operatorname{RED}(B)=\left\{i_{1}, i_{5}\right\},\left\{i_{2}, i_{5}\right\},\left\{i_{3}, i_{5}\right\},\left\{i_{4}, i_{5}\right\}$. Analogously for the output IS, $B=\left\{o_{1}, o_{2}, \ldots, o_{6}\right\}, \quad U / I N D(B)=\{T 1, T 2, T 3, T 4\}, \quad \operatorname{CORE}(B)=\left\{o_{1}, o_{2}, o_{3}\right\}$, $R E D(B)=\left\{o_{1}, o_{2}, o_{3}\right\}$. Under the assumption of $\alpha=0.5$, the results of fuzzy SE-DEA for each $R E D(B)$ are given in Tables 3 and 4 .

Table 3. Upper and lower bounds of efficiency — values

\begin{tabular}{|l|r|r|r|r|r|r|r|r|}
\hline & \multicolumn{2}{|c|}{$i_{1}, i_{5}$}$\left\{o_{1}, o_{2}, o_{3}\right\}$ & \multicolumn{2}{|c|}{$i_{2}, i_{5}$}$\left\{o_{1}, o_{2}, o_{3}\right\}$ & \multicolumn{2}{|c|}{$i_{3}, i_{5}$}$\left\{o_{1}, o_{2}, o_{3}\right\}$ & $\multicolumn{2}{|c|}{i_{4}, i_{5}} .\left\{o_{1}, o_{2}, o_{3}\right\}$ \\
\hline DMU & Lower & Upper & Lower & Upper & Lower & Upper & Lower & Upper \\
\hline T1 & $31.6 \%$ & $61.4 \%$ & $33.3 \%$ & $163.6 \%$ & $33.3 \%$ & $245.5 \%$ & $31.6 \%$ & $61.4 \%$ \\
\hline T2 & $93.3 \%$ & $300.0 \%$ & $109.0 \%$ & $600.0 \%$ & $145.7 \%$ & $900.0 \%$ & $93.3 \%$ & $300.0 \%$ \\
\hline T3 & $78.7 \%$ & $1000.0 \%$ & $63.0 \%$ & $1000.0 \%$ & $63.0 \%$ & $1000.0 \%$ & $78.7 \%$ & $1000.0 \%$ \\
\hline T4 & $133.3 \%$ & $600.0 \%$ & $33.3 \%$ & $300.0 \%$ & $33.3 \%$ & $300.0 \%$ & $133.3 \%$ & $600.0 \%$ \\
\hline
\end{tabular}

Table 4. Upper and lower bounds of efficiency - statistics

\begin{tabular}{|l|r|r|r|r|r|}
\hline DMU & Average & Lower average & Upper average & Min & Max \\
\hline T1 & $82.7 \%$ & $32.4 \%$ & $133.0 \%$ & $31.6 \%$ & $245.5 \%$ \\
\hline T2 & $317.7 \%$ & $110.3 \%$ & $525.0 \%$ & $93.3 \%$ & $900.0 \%$ \\
\hline T3 & $535.4 \%$ & $70.8 \%$ & $1000.0 \%$ & $63.0 \%$ & $1000.0 \%$ \\
\hline T4 & $266.6 \%$ & $83.30 \%$ & $450.0 \%$ & $33.3 \%$ & $600.0 \%$ \\
\hline
\end{tabular}


Four different proposals of reducts differentiating the input set were obtained. The most adequate subset must be found. It would be reasonable to use expert knowledge. In the presented example, the high dispersion of results indicates a significant uncertainty of the assessment. Considering the average, the best technology is T3; however, due to the large range of the best and worst assessments, technology T2 should also be considered

\section{Conclusions}

Technology assessment is often based on a large dataset with vague and imprecise data due to the lack of information or human subjective judgment. This paper built a two-stage hybrid rough SE fuzzy DEA model for the technology analysis.

The concept of the rough set theory has been proved to be a useful tool for the analysis of information tables describing a set of objects by multi-valued attributes and has been applied in many applications, mainly in machine-learning expert systems. The rough set theory can be successfully used to reduce the number of dimension criteria and to remove some duplicate, correlated information in complex technology assessment systems. The numerical experiments provided that the hybrid approach integrating DEA and rough set algorithms are a possible solution for the technology analysis task. In the example, the set of 12 criteria was reduced to 5. Using SE fuzzy DEA the range of score for each technology was obtained. One of the most popular fuzzy DEA models was employed to show the limiting of the cardinality of the criteria sets by rough sets concept. Other fuzzy approaches and DEA models can be tested to check the stability of solutions.

In future works, the recommendations and suggestion for reduct selection in DEA context should be developed. In addition, to increase confidence in the results, it is worth comparing and assessing the consistency of results from the proposed approach and other proposition of limitation criteria set. It is also worth mentioning the possibility of combining the PCA method and the rough set concept for the reduction of attributes in the DEA framework.

\section{References}

1. A. Kononiuk, A. Gudanowska, (eds), Kierunki rozwoju nanotechnologii $w$ województwie podlaskim. Mapy. Marszruty. Trendy, Oficyna W ydawnicza Politechniki Białostockiej, Białystok (2013)

2. J. Nazarko, Regionalny foresight gospodarczy. Scenariusze rozwoju innowacyjności mazowieckich przedsiębiorstw, ZPW iM , W arszawa (2013)

3. L. Nazarko, Future-Oriented Technology A ssessment, Procedia Engineering, 182, 504-509 (2017)

4. A. L. Porter, Technology A ssessment, Impact A ssessment, 13(2), 135-151 (1995)

5. $M$. A altonen, Evaluation and organization of Futures Research $M$ ethodology $-V 3.0$ [online] http://www.millennium-project.org/millennium/FRM -eval.pdf [11.07.2018] (2009)

6. A. M agruk, Innovative classification of technology foresight methods, Technological and Economic Development of Economy, 17(4), 700-715 (2011)

7. K. Halicka, Innovative classification of methods of the Future-oriented Technology A nalysis, Technological and Economic Development of Economy, 22(4), 574-597, (2016)

8. R. Popper, How are foresight methods selected?, Foresight, 10(6), $62-89$ (2008) 
9. C. Cagnin, A. Havas, O. Saritas, Future-oriented technology analysis: Its potential to address disruptive transformations, Technological Forecasting \& Social Change, 80(3), 379-385 (2013)

10. A. K ononiuk, A. Sacio-Szymańska, J. Gáspár, How do companies envisage the future? Functional foresight approaches, Engineering $M$ anagement in Production and Services, 9(4), 21-33 (2017)

11. N. Li, K. Chen, M. K ou, Technology foresight in China: A cademic studies, governmental practices and policy applications, Technological Forecasting and Social Change, 119, 246-255 (2017)

12. L. Proskuryakova, Energy technology foresight in emerging economies, Technological Forecasting and Social Change, 119, 205-210 (2017)

13. B. Förster, Technology foresight for sustainable production in the German automotive supplier industry, Technological Forecasting and Social Change, 92, 237-248 (2015)

14. M. Choi, H.-L. Choi, H. Y ang, Procedural characteristics of the 4th Korean technology foresight, Foresight, 16(3), 198-209 (2014)

15. D. S. K won, J. H. Cho, S. Y. Sohn, Comparison of technology efficiency for $\mathrm{CO}_{2}$ emissions reduction among European countries based on DEA with decomposed factors, Journal of Cleaner Production, 151, 109-120 (2017)

16. E. Chodakowska, J. Nazarko, Environmental DEA M ethod for A ssessing Productivity of European Countries, Technological and Economic Development of Economy, 23(4), 589-607 (2017)

17. T. Sueyoshi, M. Goto, Environmental assessment for corporate sustainability by resource utilization and technology innovation: DEA radial measurement on J apanese industrial sectors, Energy Economics, 46, 295-307 (2014)

18. J.-L. Fan, X. Zhang, J. Zhang, S. Peng, Efficiency evaluation of $\mathrm{CO}_{2}$ utilization technologies in China: A super-efficiency DEA analysis based on expert survey, Journal of $\mathrm{CO}_{2}$ Utilization, 11, 54-62 (2015)

19. A. Shabani, R. F. Saen, A new data envelopment analysis (DEA) model to select ecoefficient technologies in the presence of undesirable outputs, Clean Technologies and Environmental Policy, 16(3), 513-525 (2014)

20. Y . Liu., C. Sun, S. X u, E co-Efficiency A ssessment of Water Systems in China, Water Resource M anagement, 27(14), 4927-4939 (2013)

21. S. K. Lee, G. Mogi, K. S. Hui, A fuzzy analytic hierarchy process (A HP)/data envelopment analysis (DEA) hybrid model for efficiently allocating energy R\&D resources: In the case of energy technologies against high oil prices, Renewable and Sustainable Energy Reviews, 21, 347-355 (2013)

22. H. Lee, C. Lee, H. Seol, Y . Park, On the $R \& D$ priority setting in technology foresight: a DEA and A NP approach, International J ournal of Innovation and Technology M anagement, 5(2), 201-219 (2008)

23. P. Y U, J. H. L ee, A hybrid approach using two-level SOM and combined A HP rating and AHP/DEA-AR method for selecting optimal promising emerging technology, Expert System with A pplications, 40, 300-314 (2013)

24. G. R. A min, A. Emrouznejad, A new DEA model for technology selection in the presence of ordinal data, International J ournal of A dvanced M anufacturing Technology, 65, 1567-1572 (2013) 
25. E. E. Karsak, S. S. A hiska, Practical common weight multicriteria decision-making approach with an improved discriminating power for technology selection, International J ournal of Production Research, 43(8), 1537-1554 (2005)

26. A. A linezhad, A. M akui, R. K iani M avi, M. Zohrehbandian, A n M CDM -DEA approach for technology selection, J ournal of Industrial Engineering International, 7(12), 32-38 (2011)

27. M. K houja, The use of data envelopment analysis for technology selection, Computers \& Industrial Engineering, 28(1), 123-132 (1995)

28. R. F. Saen, Technology selection in the presence of imprecise data. weight restrictions. and nondiscretionary factors, The International Journal of A dvanced M anufacturing Technology, 41(7-8), 827-838 (2009)

29. K. K lincewicz, A. M anikowski, Ocena. rankingowanie i selekcja technologii, Wydawnictwo Naukowe Wydziału Zarządzania Uniwersytetu Warszawskiego, Warszawa (2013)

30. K. K lusacek, Selection of research priorities - method of critical technologies, Technology Centre of the CAS, [online] (2003) https://www.tc.cz/files/istec_publications/unido-course-critical-technologies-10291.pdf [13.07.2018]

31. J. Nazarko, A. M agruk (eds), Kluczowe Nanotechnologie w gospodarce Podlasia, Oficyna Wydawnicza Politechniki Białostockiej, Białystok (2013)

32. N. A dler, B. Golany, Evaluation of deregulated airline networks using data envelopment analysis combined with principal component analysis with an application to Western Europe, European J ournal of Operational Research, 132(2), 260-273 (2001)

33. N. A dler, B. Golany, Including Principal Component Weights to improve discrimination in Data Envelopment A nalysis, Journal of the Operational Research Society, 53(9), 985-991 (2002)

34. K. Revett, Diagnostic Feature A nalysis of a D obutamine Stress Echocardiography Dataset U sing Rough Sets, In: J. F. Peters, A. Skowron, H. Rybiński, eds, Transactions on Rough Sets IX, Springer, 318-327 (2008)

35. H.-H. Y ang, Ch.-L. Wu, Rough sets to help medical diagnosis - Evidence from a Taiwan's clinic, Expert Systems with A pplications, 36, 9293-9298 (2009)

36. A. I. Dimitras, R. Slowinski, R. Susmaga, C. Zopounidis, B usiness failure prediction using rough sets, European J ournal of Operational Research, 114, 263-280 (1999)

37. R. W. Swiniarski, A. Skowron, Rough set methods in feature selection and recognition, Pattern Recognition L etters, 24(6), 833-849 (2003)

38. E. Chodakowska, Rough and Fuzzy DEA in the Process of Prospective Technology A nalysis, In: A. Emrouznejad, and E. Thanassoulis (eds), Data Envelopment Analysis and Performance Measurement: Recent Developments: Proceedings of the DEA40: International Conference of Data Envelopment Analysis, A pril 2018, A ston B usiness School, Birmingham, UK (2018)

39. Z. Pawlak, Rough sets, International J ournal of Information and Computer Science, 11, 344-356 (1982)

40. Z. Pawlak, A. Skowron, Rudiments of rough sets, Information Sciences, 177, 3-27 (2007)

41. A. Charnes, W. W. Cooper, E. R hodes, M easuring the efficiency of decision-making units, European J ournal of Operational Research, 2(6), 429-444 (1978) 
42. P. A ndersen, N. C. Petersen, A procedure for ranking efficient units in data envel opment analysis, M anagement Science, 39(10), 1261-1264 (1993)

43. A. A zadeh, S. M. Alem, A flexible deterministic. stochastic and fuzzy Data Envelopment A nalysis approach for supply chain risk and vendor selection problem: Simulation analysis, Expert Systems with A pplications, 37(12), 7438-7448 (2010) 